\title{
O lugar do conceito de ideologia na análise do discurso politico (ADP): uma proposta à luz da análise critica do discurso (ACD)
}

The place of the concept of ideology for the political discourse analysis (pda): a proposal in the light of the critical discourse analysis (cda)

Vilmar Ferreira de Souza Instituto Federal de Educação, Ciência e Tecnologia do Ceará - Campus Crateús

RESUMO: No presente trabalho proponho discutir o lugar do conceito de ideologia na Análise do Discurso Político (ADP), conforme desenvolvido em DeSouza (2011a) e, posteriormente retomado em DeSouza (2011b), ambos ancorados na visão neomarxista de ideologia, que comporta, como uma de suas dimensões basilares, a dimensão discursiva. A base teórica deste trabalho repousa na Gramática Sistêmico-Funcional (HALLIDAY; MATTHIESSEN, 2004) e na Análise Crítica do Discurso (FAIRCLOUGH, 2001). Finalizo este texto sugerindo uma representação gráfica do conceito de ideologia, bem como convidando a comunidade acadêmica a inspecionar suas possibilidades investigativas.

PALAVRAS-CHAVE: Análise do Discurso Político (ADP), ideologia; Análise Crítica do Discurso (ACD).

ABSTRACT: In this work, I discuss the place of the concept of ideology for the field of Political Discourse Analysis (PDA), in line with the investigation carried out in DeSouza (2011a) and, subsequently, in DeSouza (2011b), both works based on the neo-Marxist view of ideology, which encompasses, as one of its basic dimensions, that of discourse. The theoretical basis for the present discussion lies in the Systemic-Functional Grammar (HALLIDAY; MATTHIESSEN, 2004) and Critical Discourse Analysis (FAIRCLOUGH, 2001). I 
conclude these lines by suggesting a graphic representation of ideology, and by inviting the academic community to explore the investigative potential of the concept.

KEY WORDS: Political Discourse Analysis (PDA), ideology, Critical Discourse Analysis (CDA).

\section{Introdução}

Não constitui surpresa saber que um volume inteiro intitulado Ideologia e Contra Ideologia (BOSI, 2010) tenha usado a metáfora "nó ideológico" para sinalizar a complexidade de se definir ideologia e localizar seu devido lugar,

Vilmar

Ferreira de

Souza no tempo e no espaço, no seio das ciências sociais. Esta mesma sensação de impossibilidade de abarcar e 'domesticar' o conceito de ideologia também é compartilhada por Koerner (2001), que, do mesmo modo, informa que Boudon (1986), ao se aventurar a definir ideologia em uma monografia de 330 páginas, também não logrou sucesso em oferecer uma definição universalmente aceita. Entretanto, o mesmo autor reconhece que, mesmo diante desse quadro desolador, a necessidade de se debruçar sobre esse conceito é premente, dado seu rico potencial analítico-investigativo.

Para além da impossibilidade de definir ideologia e de 'domesticá-lo', em Desouza (2011a) ${ }^{1}$, procurei transformá-lo em uma ferramenta de análise linguístico-discursiva, a partir da investigação das relações de poder no discurso político do Padre Cícero, a figura mais influente da política do Nordeste brasileiro no início do século passado. Naquele trabalho, embasado teoricamente na Gramática Sistêmico-Funcional (HALLIDAY; MATTHIESSEN, 2004) e na Análise Crítica do Discurso (FAIRCLOUGH, 2001), primeiramente selecionei algumas definições do termo, fazendo algumas paradas obrigatórias; em seguida, dessas breves paradas resultaram alguns elementos conceituais que perpassam as definições escolhidas para, a partir daí, oferecer uma representação gráfica ad hoc do conceito, conforme pensado e elaborado em DeSouza (2011a). O objetivo desse percurso foi transformar o conceito de ideologia em uma categoria de análise linguístico-discursiva na intersecção entre língua e sociedade. Além do mais, o conceito foi discutido ali como funcionando como o contexto de cultura da referida pesquisa, em alinhamento com a Gramática Sistêmico-Funcional e como a base da dimensão da prática sociocultural do construto analítico desenvolvido por Fairclough (2001, por exemplo).

1. Agradeço aos professores Dr. José Luiz Meurer (UFSC, in memoriam), Dr. Pedro Henrique Lima Praxedes Filho (UECE) e Dra. Maria Lúcia Barbosa de Vasconcellos (UFSC), pelas valiosas contribuições que me deram como orientadores do meu processo de doutoramento. 
A pesquisa que gerou a presente discussão teve como objetivo principal investigar como as relações de poder, forjadas no discurso político do Padre Cícero, durante o ápice de sua luta pela libertação de Juazeiro do Norte do município do Crato, em 1910, foram discursivamente realizadas. Da Gramática Sistêmico-Funcional, utilizei os sistemas de transitividade e os de modo e modalidade como instâncias descritivas e, da Análise Crítica do Discurso, os conceitos de ideologia e de hegemonia como pensados e elaborados a partir de Fairclough (2001) como parâmetros interpretativos.

Dito isto, fica claro que as linhas que se seguem têm como única pretensão discutir o que foi pensado sobre o conceito de ideologia para aquele trabalho, em particular, e não pretende esgotar as possibilidades investigativas do conceito para outros trabalhos, investigando

O lugar do conceito de ideologia na análise do discurso político (adp) outros objetos de estudo. O que se segue está organizado da seguinte forma: primeiro, faço um pequeno percurso no tempo e no espaço, com algumas paradas obrigatórias, para verificar como o conceito nasceu e evoluiu, assinalando os traços comuns de suas várias definições; segundo, esses traços servirão de base para uma proposta de representação gráfica do conceito; em seguida, discuto como o conceito de ideologia, conforme pensado e elaborado aqui, serviu de parâmetro interpretativo para a discussão dos achados em DeSouza (2011a) e, por último, concluo este texto com um convite para que se expandam as considerações feitas neste trabalho à procura das possibilidades investigativas do conceito de ideologia.

\section{O conceito de ideologia - um longo caminho com breves paradas}

Existe consenso que a origem do termo ideologia pode ser atribuída ao filósofo francês Desttut de Tracey (1888, citado em KOERNER, 2001) que definiu «idéologies' como simplesmente «um conjunto de ideias», um conceito que nasceu em um contexto educacional e possuía uma conotação positiva e benéfica. Entretanto, nas mãos de $\mathrm{Na}$ poleão Bonaparte, o conceito foi revestido com conotações negativas. Para Napoleão, seguindo o mesmo autor, a ideologia pertencia ao domínio das ideias abstratas (ou ideológicas), contrastando com o mundo de questões práticas (a política) e, por causa de sua natureza abstrata, a ideologia não se prestava à resolução de problemas práticos de cunho político. 
Esta dimensão negativa e enganosa de ideologia se fortaleceu ainda mais nos trabalhos de Karl Marx e Frederic Engels, reconhecidamente os precursores do chamado materialismo histórico, doutrina considerada a base do socialismo, sistema político que conheceu seu apogeu a partir da revolução socialista na ex-União Soviética em 1917. Para esses autores, a força que determina a organização social dos homens e as condições concretas de produção do capital é a economia. Por esse motivo, não é surpresa que, examinando os fenômenos Vilmar sociais com esse olhar materialista, a percepção desses autores sobre Ferreira de a ideologia como um «conjunto de ideias» não passava de uma «falsa Souza consciência», um olhar equivocado da realidade que mascarava a análise científica das condições materiais de produção, e, por causa dessa 424 característica, a ideologia constituía um sério impedimento à mudança social e, por consequente, era prejudicial ao sistema socialista.

De fato, como observa Thompson (1990, p. 45), a ideologia para Marx "é o sintoma de uma doença, não a característica normal de uma sociedade saudável e menos ainda o medicamento de uma cura social». ${ }^{2}$ O mesmo autor informa ainda que Marx e Engels abordam o conceito de ideologia em vários pontos de sua vasta obra e o elaboram de várias maneiras, mas, no entanto, em todas elas, a conotação negativa desde a formulação política de Napoleão se torna inalterada.

O pensamento político ocidental se apropriou dessa dimensão negativa do conceito de ideologia da seguinte maneira: para o Ocidente, liderado pelos Estados Unidos, que mantinha com o regime de Moscou uma relação de "guerra fria", após a revolução de 1917, o regime ali instalado significava uma ditadura política, a estagnação econômica e a irracionalidade social. Por outro lado, o regime político ocidental representava uma democracia política com expansão econômica e liberalismo social. Ao se referir ao movimento socialista de Moscou, por sua vez, o ocidente o caracterizava como uma luta ideológica, imprimindo, desse modo, o mesmo tom de negatividade que tem acompanhado o conceito desde os tempos de Napoleão Bonaparte.

Graças a um movimento revisionista recente, empreendido em grande parte por um grupo de autores denominado neomarxistas, o conceito de ideologia tem sido discutido em outras bases teóricas. Um dos principais pontos de afastamento do materialismo histórico e da de-

\footnotetext{
2. Aqui e em todo o resto do texto, as traduções são de minha inteira responsabilidade.
} 
terminação do status central da economia na análise dos fatos sociais é a compreensão de que, além da dimensão econômica, outras formas de organização do tecido social como, por exemplo, a dimensão discursiva, mereceria ter seu espaço reconhecido no contexto de análise científica e materialista da realidade social.

Para além desse "conjunto de ideias nebuloso", o sociólogo italiano Antônio Gramsci, por exemplo, considera que a ideologia não pode ser vista descontextualizada e que ela se manifesta na própria realidade material dos indivíduos, na qual ela é criada e reproduzida através de seus atores sociais. A consequência imediata desse novo olhar é que, ao lado da dimensão econômica que dominava a abordagem sobre ideologia de Marx e Engels, poderiam conviver, harmonicamente, outras dimensões como a cultural, da qual o componente discursivo constitui Olugar do conceito de ideologia na análise do discurso político (adp) um elemento legítimo e intrínseco e com grande valor analítico para se investigar os fenômenos sociais.

Alinhando-se com essa nova visão de ideologia, Fairclough (1989, p. 84), seguindo os passos dos autores acima, define ideologia como "uma concepção do mundo que é implicitamente manifesta na arte, na lei, da atividade econômica e em todas as manifestações da vida individual e coletiva». Em uma reflexão posterior sobre o mesmo tema, o autor distingue, a partir dessa definição, uma ideologia «descritiva» de outra dita «crítica». Para ele, uma dimensão descritiva do conceito o considera como um conjunto de atitudes, crenças etc., enquanto que uma visão crítica aborda o conceito como um espaço para a criação, a manutenção e a mudança das relações sociais de poder, dominação e exploração (FAIRCLOUGH, 2003).

Em direção diferente da de Fairclough, (1989, 2001), mas igualmente mantendo distância da conotação negativa que tem acompanhado o conceito até então, van Dijk (1998/2000, p. 1) define ideologia sem alusão a sua dimensão sociológica nem à filosófica, ao postular que

\footnotetext{
[...] esta abordagem [a ideologia] não deriva sua principal inspiração da sociologia ou filosofia, mas do novo domínio do estudo da cognição social na psicologia social. Nessa perspectiva, as ideologias são definidas como as estruturas básicas que organizam as representações sociais nas mentes dos membros do grupo social, ou seja, em função dos objetivos sociais e políticos e interesses de grupos ou instituições.
} 
Dirven, Hawkins e Sandikcioglu (2001), em Linguagem e Ideologia, também situam a discussão de ideologia dentro do paradigma da linguística cognitiva, não apenas reconhecendo a centralidade do conceito, mas também convidando os colaboradores daquele volume a refletirem sobre a tensão inerente a ele, que, para aqueles autores, articula simultaneamente elementos conscientes e inconscientes. Pires de Oliveira (mesmo volume, p. 37), ao entrevistar George Lakoff sobre o tema, obtém deste a seguinte resposta: “[...] para mim, essa é a parte

Vilmar interessante das ideologias - a parte escondida, inconsciente. É aí que os Ferreira de

Souza linguistas cognitivistas têm uma contribuição a dar".

Longe de cobrir as possibilidades de definição do conceito de ideologia, as paradas acima ao menos mostram claramente a mudança de abordagem do conceito, de uma interpretação sociológica nociva ao tecido social, na visão napoleônica e marxista, ao papel central atribuído a ele no modelo tripartite de análise de Fairclough e no campo da linguística cognitiva. E foi a partir dessas paradas que extraí o material necessário para a representação gráfica do conceito de ideologia, como apresento a seguir.

\section{Ideologia - rumo a uma proposta multiestratal do conceito}

É possível agora, com base nas definições apresentadas acima, elencar algumas características que permeiam o estudo do conceito de ideologia, independentemente de sua definição. Elas são: (a) a definição de ideologia incorpora tanto elementos cognitivos quanto sociais; (b) por causa de sua natureza cognitiva e social, a ideologia é um locus natural de produção, desenvolvimento e reprodução de crenças e valores de um determinado grupo social; (c) ao contrário da conotação negativa marxista do conceito, a ideologia, como abordada neste trabalho, pode ser negativa e/ ou positiva, uma vez que para cada aspecto de dominação pode conviver uma dimensão de subversão a essa mesma dominação; (d) o conteúdo ideológico pode ser acessado na vida real através do discurso como realização de um componente intrínseco das práticas sociais e (e) a ideologia constitui assim delimitada, um conceito multiestratal, não podendo, por isso mesmo, ser estudada por nenhuma perspectiva em particular.

Dito isso, e alinhando a presente discussão com DeSouza (2011a), que investigou as relações de poder forjadas no discurso político do Padre Cícero, podemos afirmar que as várias dimensões que podem constituir aspectos de uma teoria da ideologia, e que foram producentes para o trabalho em foco, foram: (1) a antropológica; (2) a política; (3) a 
social; (4) a religiosa, (5) a histórica e (6) a semiótico-discursiva. A Figura $1^{3}$ mostra a representação gráfica do conceito de ideologia, conforme elaborado em DeSouza (2011a).

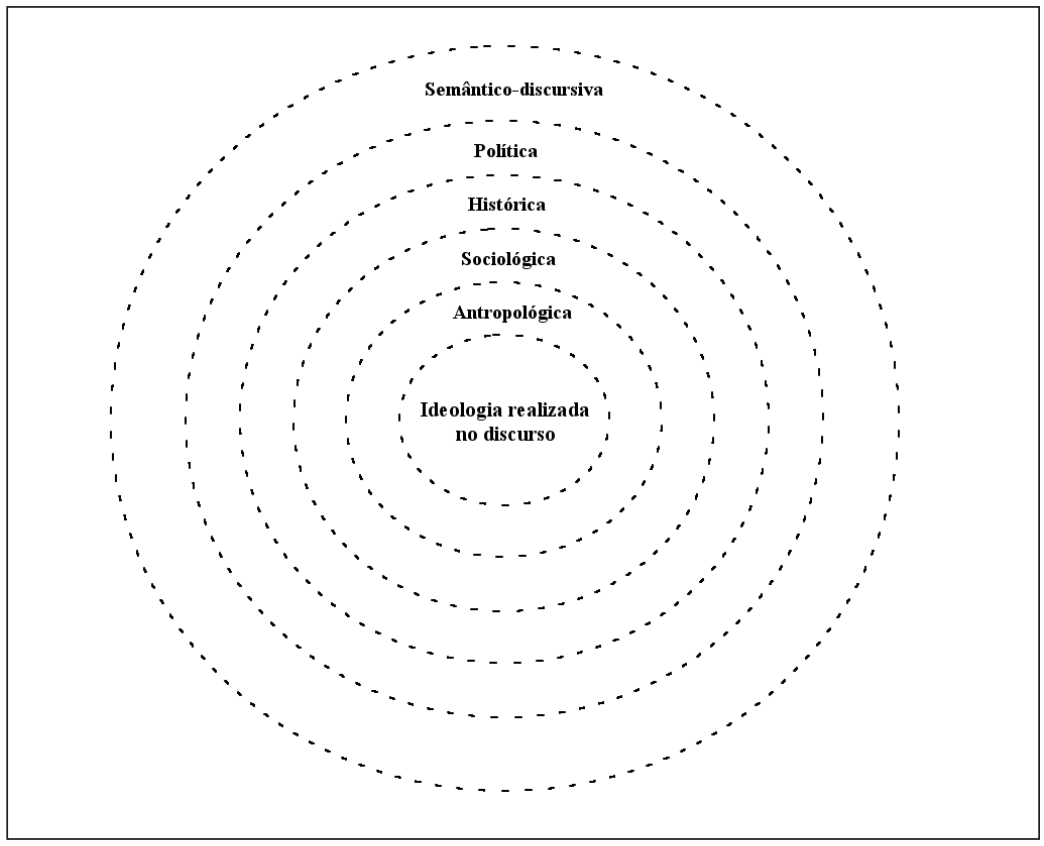

Olugar do conceito de ideologia na análise do discurso político (adp)

Figura 1 A representação gráfica do conceito de ideologia, com base em DeSouza (2011a)

A Figura 1 mostra, em resumo, que a manifestação discursiva da ideologia na vida material e social pode ser observável através de qualquer prática social, seja ela um encontro mediado pelo discurso, seja modos de vestir, e assim por diante. A relação, pois, entre os vários níveis representados acima, só pode se caracterizar pelo princípio da simultaneidade. Noutras palavras, o simples uso de uma determinada variedade da língua pode ter uma função específica dentro da comunidade linguística do falante, e esta função pode estar atendendo demandas ideológicas localizadas em qualquer um dos níveis da Figura 1.

Assim determinado, caracterizado e representado graficamente, o conceito de ideologia ainda carece de uma observação adicional. Antes de mais nada, a representação gráfica construída aqui, por tudo o que já foi discutido anteriormente, não pode passar apenas de uma proposta ad

3. Agradeço ao graduando em Letras do IFCE-Campus Crateús, José Roberto Romeu Gomes, pela confecção da Figura 1. 
hoc, construída sob medida para auxiliar na reflexão acerca do discurso político do Padre Cícero e, por causa disso, não pretende, nem pode, ser vista como um construto acabado. Muito pelo contrário, se houver mérito nessa proposta é o de que ela sirva de ponto de partida para a reflexão de outras agendas de pesquisa que também vejam o conceito de ideologia com esse grande potencial analítico-discursivo e que, ao refletirem sobre esse ponto, reelaborem a proposta aqui apresentada da melhor maneira a atender suas necessidades específicas de pesquisa, com o objetivo único

Vilmar

Ferreira de

Souza de posicionar o estudo sobre a ideologia no seu devido lugar dentro do panorama dos estudos envolvendo língua e sociedade.

No que se segue, apresento algumas contribuições do conceito de ideologia para a análise das relações de poder no discurso político do Padre Cícero, da forma como foi discutida em DeSouza (2011a).

\section{O lugar do conceito de ideologia na Análise do Discurso Polí- tico (ADP) - evidências do discurso político do Padre Cícero}

Cada uma das seis dimensões da ideologia representadas graficamente na Figura 1 contribuiu diferentemente para a construção do contexto de situação e do contexto de cultura da pesquisa desenvolvida em DeSouza (2011a).

A primeira dimensão, a antropológica, por exemplo, me informou como a luta de Juazeiro pela sua independência política constituía uma ação legítima em si mesma, revestida de relevância para a compreensão da história particular do movimento político daquela região, independentemente do ponto de vista governamental oficial negativo que a via como fanatismo religioso.

Foi focando na dimensão política do fenômeno de Juazeiro do Norte que me possibilitou, não apenas a compreender melhor o emaranhado do xadrez da política daquela região, mas também a identificar os atores sociais mais relevantes para aquela pesquisa, no caso particular, as figuras do próprio Padre Cícero, do governador da província do Ceará, coronel Nogueira Accioly, e do prefeito do Crato, município ao qual Juazeiro estava politicamente subordinado, coronel Antônio Luís.

A contribuição da dimensão sociológica recaiu sobre como a organização hierárquica da sociedade de Juazeiro do Norte, com seus dois grupos bem definidos, a saber, os nativos e os estrangeiros (esse último formado por pessoas de outras origens que vieram para Juazeiro, atraídas pelo crescimento da vila) e como essa polarização influenciava, ou não, o discurso político do Padre Cícero. 
O olhar para a dimensão religiosa do 'fenômeno' de Juazeiro me mostrou claramente as relações forjadas entre a Igreja de Roma e a de Juazeiro, bem como a relação desta com a diocese de Fortaleza, identificando aqu, que aspectos desta dimensão ideológica ressoavam, ou não, no discurso político do Padre Cícero. Ao lado desse olhar religioso, a dimensão histórica contribuiu com a compreensão do tempo e do espaço nos quais os acontecimentos se desdobraram e como eles se conjugaram para a independência política de Juazeiro do Norte, em 1911.

Por último, a dimensão semiótico-discursiva indagou sobre como os textos instanciaram, a partir dos cinco níveis anteriores, conteúdo ideológico desta luta. Por exemplo, a maneira discursivamente amigável com a qual o Padre Cícero se dirigia àquelas autoridades políticas, - usando, muitas vezes, o grupo nominal 'meu amigo' -, a saber, os

O lugar do conceito de ideologia na análise do discurso político (adp)

\section{Uma conclusão em forma de convite}

Iniciei esta discussão dialogando com Koerner (2001) que, retomando Boudon (1986), desenha um quadro desolador a respeito do conceito de ideologia, em virtude da dificuldade até mesmo de defini-lo de modo que seja universalmente aceito.

Apesar desse quadro, e continuando a pensar com o mesmo autor, reconheci que valia a pena investir no potencial investigativo do conceito de ideologia. Depois de fazer algumas paradas obrigatórias ao longo do caminho percorrido por ele, elenquei alguns elementos que perpassavam suas várias definições para, a partir daí, construir a sua representação gráfica. Não esqueci, durante esse percurso, de adverti às leitoras e aos leitores em potencial que toda a discussão sobre ideologia 
desenvolvida aqui foi fruto de um trabalho de doutoramento (DESOUZA, 2011a) e, por esse motivo, os questionamentos possivelmente levantados a partir da leitura desse texto, devem levar em conta o contexto no qual aquele trabalho foi pensado e produzido.

Antes de concluir este texto, é preciso ainda comentar alguns pontos. Toda a discussão aqui foi conduzida tomando o discurso político como base, mas nenhuma palavra foi dita sobre o que seria política nem o que seria o discurso político. Esta tarefa, por si só, já justificaria

Vilmar

Ferreira de

Souza

430 outro trabalho, mas para o escopo deste, é suficiente concordar com Chilton (2004, p. 3) que política é "uma luta por poder, entre aqueles que o detêm e lutam para mantê-lo e aqueles que procuram resistir a esse poder". Por conseguinte, discurso político abrange o conjunto de discursos produzidos por esses atores políticos no exercício de sua profissão, nos mais variados contextos sociais.

Outra questão teórica precisa ser comentada neste ponto. Da maneira que foi desenvolvido neste trabalho, o conceito multiestratal de ideologia funcionou como o contexto de cultura da Gramática Sistêmico-Funcional, provendo, ao menos para os limites daquela pesquisa, os elementos sociológicos necessários para a interpretação do discurso político do Padre Cícero, formando, desse modo, a base sociológica necessária à GSF, apontada por Meurer (2004). Longe de dar conta de uma teoria sociológica ampla como preconiza este autor, o conceito de ideologia pode servir ao menos como um parâmetro sociológico fértil para se pensar a relação intrínseca entre linguagem e sociedade.

Embora toda a discussão sobre o conceito de ideologia tenha tido como base o discurso político do Padre Cícero, acredito que as questões levantadas neste trabalho poderão ser expandidas e/ou adaptadas para outros campos que também se interessem em investigar que elementos do tecido social se conjugam na produção de discursos em várias esferas da atividade humana.

É importante que essas linhas animem um diálogo ampliado do conceito de ideologia não apenas no âmbito da Análise do Discurso Político (ADP), mas também no espectro maior das pesquisas preocupadas em pensar a relação mencionada acima. Desse diálogo ampliado emergirão várias janelas que mostrarão diversas facetas desse potencial de análise linguístico-discursiva do conceito de ideologia, como acreditam DeSouza (2011a) e Koerner (2001), para, finalmente, transformar o 'nó ideológico' numa poderosa ferramenta de análise linguístico-discursiva. 


\section{Referências}

BOSI, A. Ideologia e contraideologia. São Paulo: Companhia das Letras, 2010.

BOUDON, R. L'idéologie ou l'origine des idées reçues. Paris: Fayard, 1986.

O lugar do conceito de ideologia

CHILTON, P. Analysing political discourse: theory and practice. na análise London and New York: Routledge, 2004.

do discurso político (adp)

DESOUZA, V. F. Power relations in Padre Cícero's epistolary political discourse: an investigation in the light of SystemicFunctional Grammar and Critical Discourse Analysis. 173f. Tese (Doutorado em Letras/Inglês e Literatura Correspondente). Universidade Federal de Santa Catarina. Florianópolis-SC, 2011a.

O conceito de ideologia e seu potencial como um ponto de intersecção entre a Gramática Sistêmico-Funcional (GSF) e a Análise Crítica do Discurso (ACD). In: VII Congreso Internacional de la Asociación de Lingüística Sistémico Funcional de América Latina -ALSFAL, 2012, Santa Fé. Del género a la cláusula: los aportes de la LSF al estudio del lenguaje en sociedad: Actas del VII Congreso Internacional de la Asociación de Lingüística Sistémico Funcional de América Latina -ALSFAL. Santa Fé: Ediciones UNL, 2011. v. 1, 2011 b.

DIRVEN, R., HAWKINS, B.; SANDIKCIOGLU, E. (Eds.), Language and ideology. Filadelphia and Amsterdam: John Benjamins, 2001.

FAIRCLOUGH, N. Language and power. London: Longman, 1989.

Language and power. 2nd ed. London: Longman, 2001.

Analysing discourse: textual analysis for social research. New York: Routledge, 2003.

GRAMSCI, A. Selections from the prison notebooks. New York: International Publishers Co., 1971. 
HALLIDAY, M. A. K.; MATTHIESSEN, C. M. I. M. An introduction to Functional Grammar. $3^{\text {rd }}$. ed. London: Arnold, 2004.

KOERNER, E. F K. Linguistics and ideology in 19th and 20th century studies of language. In DIRVEN, R.; HAWKINS, B.; SANDIKCIOGLU, E. (Eds.). Language and ideology. Amsterdam/Filadelphia: John Benjamins, 2001.

Vilmar MEURER, J. L. Role prescriptions, social practices and social strucFerreira de tures: A sociological basis for the contextualization of analyses in

Souza SFG and CDA. In: YOUNG, E.; HARRISON, C. (Eds.). Systemic functional linguistics and critical discourse analysis: Studies in social change. Londres: Continuum, 2004.

PIRES DE OLIVEIRA, R. An interview with George Lakoff. In: DIRVEN, R.; HAWKINS, B.; SANDIKCIOGLU, E. (Eds.). Language and ideology. Amsterdam and Filadelphia: John Benjamins, 2001.

THOMPSON, J. B. Ideology and modern culture. Standford, California: Standford University Press, 1990.

VAN DIJK, T. A. Ideology - a multidisciplinary approach. London: Sage Publications, 1998/2000. 